\title{
Disseminated intravascular coagulation in a dog naturally infected by Leishmania (Leishmania) chagasi from Rio de Janeiro - Brazil
}

\author{
Carla O Honse ${ }^{1 *}$, Fabiano B Figueiredo ${ }^{1 \dagger}$, Nayro X de Alencar $^{2}$, Maria de Fátima Madeira ${ }^{3}$, Isabella DF Gremião \\ and Tânia MP Schubach ${ }^{1+}$
}

\begin{abstract}
Background: Disseminated intravascular coagulation (DIC) is an acquired disorder characterized by the activation of intravascular coagulation and excessive fibrin formation. It always occurs in association with other clinical conditions, including parasitic diseases. DIC has been described as a unusual complication in human and canine visceral leishmaniasis.

Case presentation: DIC was found in a seven-year-old male mongrel dog naturally infected by Leishmania (Leishmania) chagasi. Haemostasis parameters demonstrated changes in primary and secondary haemostasis and fibrinolysis.

Conclusion: DIC is a unusual condition described in canine visceral leishmaniasis and it seems to be associated with several immunological and pathological mechanisms involved in the disease.
\end{abstract}

Keywords: Disseminated intravascular coagulation, Dog, Visceral leishmaniasis

\section{Background}

Disseminated intravascular coagulation (DIC) is a syndrome characterized by the systemic activation of blood coagulation which generates intravascular fibrin leading to thrombosis in small and medium sized vessels and eventually organ dysfunction [1]. It can be also associated with severe hemorrhaging due to the consumption of platelets and coagulation factors [2]. DIC is not a primary disorder, always occurring in association with other clinical conditions, including sepsis, trauma, pregnancy complications, intravascular hemolysis, neoplasias, toxicity, hepatic diseases, cardiovascular diseases, parasitic diseases (protozoa) and others [3]. In human visceral leishmaniasis, DIC has been reported as an unusual complication [4]. In a review of hematological manifestations of visceral leishmaniasis, four human patients were

\footnotetext{
* Correspondence: carlahonse@yahoo.com.br

${ }^{\dagger}$ Equal contributors

'Laboratório de Pesquisa Clínica em Dermatozoonoses em Animais

Domésticos, Instituto de Pesquisa Clínica Evandro Chagas, Fundação

Oswaldo Cruz (Fiocruz), Av. Brasil, 4365, Manguinhos, Rio de Janeiro

21045-900, Brasil

Full list of author information is available at the end of the article
}

associated with disseminated intravascular coagulopathy [5]. Blount et al. suggested that circulating immunocomplexes can directly activate the coagulation cascade in this disease [6].

The scarcity of publications regarding this disorder in canine visceral leishmaniasis $[7,8]$ and the complex pathogenesis of both diseases, in which the liberation of inflammatory cytokines play important role in the response of host, motivated us to describe this clinical report of disseminated intravascular coagulation in a dog naturally infected by Leishmania (Leishmania) chagasi from Rio de Janeiro - Brazil.

\section{Case presentation}

A seven-year-old male mongrel dog, weighing $10 \mathrm{~kg}$, was taken to the Laboratory of Clinical Research on Dermatozoonosis in Domestic Animals, Evandro Chagas Clinical Research Institute - Oswaldo Cruz Foundation (Fiocruz), with a clinical suspicion of visceral leishmaniasis by Secretaria Municipal de Saúde do Rio de Janeiro (Municipal Health Department of Rio de Janeiro). The clinical examination revealed the presence of a single

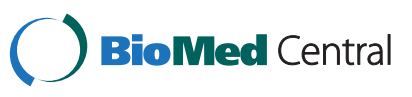


ulcerated cutaneous lesion with well-defined borders, measuring $0.5 \mathrm{~cm}$ in diameter, in the left ear, emaciation and lethargy. The mucous membranes were pale and the animal had signs of hepatomegaly and splenomegaly. There was no evidence of epistaxis, and the rectal temperature was $38.8^{\circ} \mathrm{C}$.

Bleeding time (BT) was assessed with an automated spring-loaded device $(2.4 \mathrm{~mm}$ - Unistik 2 Normal, Owem Mumford) in dry, clean and hairless skin of the inner right ear. Blood from the incision was blotted with Whatman $\mathrm{n}^{\circ} 2$ filter paper every thirty seconds untill all bleeding stopped $[9,10]$. BT was 600 seconds (reference value 138 seconds).

Blood samples were collected by cephalic venipuncture and placed in three sets of tubes, one without anticoagulant for serological reassessment (Indirect ImmunoFluorescence - IIF), another with ethylenediaminetetraacetic acid (10 percent) for hematological evaluation and the third with sodium citrate (3.2 per cent) for coagulation tests. The serum sample was tested for anti-Leishmania antibodies with the IFI-Leishmaniose-Visceral-CaninaBio-Manguinhos test (Bio-Manguinhos, Rio de Janeiro, Brazil) and the dog was seroreactive with titer $\geq 1 / 160$. According to standards established by Ministério da Saúde (Health Department) [11], this canine patient was humanely euthanized with an intravenous administration of sodium thiopental $5 \%$. After euthanasia, cutaneous lesion and spleen fragments were collected and immersed in saline containing $100 \mu \mathrm{g}$ of 5 fluorocytocine, $1000 \mathrm{IU}$ of penicillin and $200 \mu \mathrm{g}$ of streptomycin per milliliter and stored at $4^{\circ} \mathrm{C}$ for $24 \mathrm{~h}$. Afterwards, the fragments were transferred aseptically to a biphasic culture medium (NNN supplemented Schneider's medium with 10\% fetal bovine serum) and stored at $26-28^{\circ} \mathrm{C}$. The fresh culture was monitored weekly for thirty days. Multi-locus enzyme electrophoresis (MLEE) was adopted for characterization of isolates, in accordance with Cupolillo et al. [12]. The parasite was isolated and, after isoenzyme analysis, was identified as Leishmania (Leishmania) chagasi.

The serum sample was also tested for the Dirofilaria immitis antigen as well as the antibodies against Borrelia burgdorferi and Ehrlichia canis (SNAP 3Dx - IDEXX), the results being negative.

Complete blood count $(\mathrm{CBC})$ was performed with an automated cell counter (Coulter Model T-890) and the blood smears were stained by the Romanowsky method with Giemsa stain (Giemsa Stain Modified, Sigma-Aldrich ). Hematological findings included PCV 26\% (reference value $46 \%$ ), $\mathrm{RBC} 3.6 \times 10^{6} / \mu \mathrm{L}$ (reference value $6.5 \times 10^{6} / \mu \mathrm{L}$ ), hemoglobin $8.4 \mathrm{~g} / \mathrm{dL}$ (reference value $15.4 \mathrm{~g} / \mathrm{dL}$ ), platelets $128 \times 10^{3} / \mu \mathrm{L}$ (reference value $273 \times 10^{3} / \mu \mathrm{L}$ ) and total plasmatic protein $9.0 \mathrm{~g} / \mathrm{dL}$ (reference value $7.1 \mathrm{~g} / \mathrm{dL}$ ).

Prothrombin time (PT) (Thromborel ${ }^{\circledR}$ S, Dade Behring) and activated partial thromboplastin time (APTT)
(Pathromtin SL, Dade Behring) were determined with a fully-automated coagulation system - Sysmex Serie CA 500 (Sysmex America, Inc.). A group of healthy dogs $(n=18)$ was recruited for reference values of the hemostasis parameters. The animals, clinically and laboratory healthy (data not shown), were serologically negative for the Dirofilaria immitis antigen as well as antibodies against Borrelia burgdorferi and Ehrlichia canis (SNAP 3Dx - IDEXX) and not reactive to Leishmania sp. by the IIF test (Bio-Manguinhos, Rio de Janeiro, Brazil). PT and APTT were considered prolonged when the subject's time was at least 30\% longer than the healthy control's time [2]. Hemostatic abnormalities included prolonged activated partial thromboplastin time 128.0 seconds (reference value, 37.2 seconds) and prolonged prothrombin time 9.8 seconds (reference value, 7.3 seconds).

The Dade ${ }^{\circledR}$ DIMERTEST latex assay was adopted for the rapid qualitative evaluation of circulating derivatives of fibrin degradation products (XL-FDP) (Dade Behring). The result was positive with sample agglutination.

\section{Discussion}

Disseminated intravascular coagulation (DIC) is a hematological syndrome characterized by the activation of intravascular coagulation resulting in excessive fibrin formation and simultaneous consumption of coagulation factors and platelets resulting in severe hemorrhaging. DIC can be either acute (decompensated) or chronic (compensated) [13]. In general, several simultaneously occurring mechanisms play a role in the pathogenesis of disease. Fibrin deposition is a result of tissue factor/FVIIa complexmediated thrombin generation and dysfunctional physiological anticoagulant pathways (mainly antithrombin III and protein C) [14]. A third important inhibitor of coagulation is tissue factor pathway inhibitor (TFPI), although its role in the pathogenesis of DIC is not clear. In addition, the inhibition of fibrinolytic activity by increased plasma levels of plasminogen activator inhibitor type 1 (PAI-1) results in a inadequate removal of fibrin contributing to thrombosis in small and medium sized vessels [14]. The activation and liberation of inflammatory cytokines in pathogenesis of DIC is unquestionable. According to van der Poll et al. [15], coagulation proteins (FXa, thrombin and Fibrin) can activate endothelial cells, stimulating the synthesis of proinflammatory cytokines and growth factor.

Several clinical conditions may lead to the development of DIC, including parasitic diseases. Activation of coagulation and subsequent fibrin deposition are essential parts of the host defense against infectious agents in an attempt to contain the invading microorganisms and the subsequent inflammatory response [1]. However, an exaggerated response can lead to a situation in which coagulation itself contributes to its most severe form of 
the disease causing microvascular thrombosis, organ dysfunction and bleeding [16]. Clinical signs such as epistaxis [17-19], haematuria $[18,20]$ and disseminated intravascular coagulation [7] as well as laboratory abnormalities in haemostasis $[7,8,21]$ have been reported in dogs with canine visceral leishmaniasis, suggesting that this protozoan affects not only primary and secondary haemostasis but fibrinolysis as well. In this report, the dog did not present clinical evidence of haemostatic abnormalities. This can be explained by a balance between destruction and production of coagulation factors and platelets resulting in a chronic or compensated status. The pathophysiology of compensated DIC and decompensated DIC is fundamentally the same, but acute DIC results from generation of a large amount of thrombin in a brief time period leading to hypercoagulable state and thrombosis, that can be followed by the development of a so-called hypocoagulable phase caused by depletion of clotting factors leading to bleeding, while the chronic DIC results of exposure of the coagulation system to small amounts of tissue factor, in which the coagulation factors and platelets are more able to be replaced in the majority of patients [13].

Hepatomegaly, splenomegaly and nephropathy have been often reported in dogs with canine visceral leishmaniasis [22,23]. Leishmania organisms can infect many different types of cells, including those of the mononuclear phagocityc system (macrophages and Kupffer cells), endothelial cells, hepatocytes, dendritic cells and others [24,25]. Activated mononuclear cells and endothelial cells induce expression of tissue factor that activates platelets and the coagulation system. Hepatomegaly is the result of inflammatory cell infiltration, permanent cell hypertrophy/ hyperplasia and possible passive congestion [23,26]. Chronic granulomatous inflammation may be initially restricted within sinusoids and then expand to involve portal area, capsule or become diffuse $[27,28]$, resulting in coagulation factor deficiency. Splenomegaly is caused by proliferation and/or infiltration of immune cells and is associated to hyperplasia of white and red pulp by changes in microvascular structure [29]. Spleen has been proposed as a key organ to allow long-term parasite survival due to an ineffective immune response and it has been correlated with the number of macrophages expressing complement receptors [30]. Nephropathy, which has been associated to immune-mediated mechanims, is characterized by presence of membranoproliferative glomerulonephritis and tubulointerstitial nephritis (rarely amyloidosis) [31] that can enable the loss of antithrombin III, a potent inhibitor of serine proteases in the coagulation cascate, contributing to the development of DIC. In the present case, clinical signs of hepatomegaly and splenomegaly were observed, but hepatic and renal enzymes and histopathological analysis were not performed.
As mentioned before, DIC is not a disease in itself, but always occurs secondary to an underlying disorder. Clinical evidence of metabolic disease, co-infeccions such as Babesia sp., neoplasias (e.g. lymphoma), immunological reactions, toxic reactions or trauma were not observed in the case reported here.

Previous studies on haemostasis in canine visceral leishmaniasis have obtained different results, indicating that many factors may play a role in the etiology of hemorrhagic manifestations, such as epistaxis, associated with the disease. According to Font et al. [7], epistaxis seems to be a result of inflammatory and ulcerative lesions of the nasal mucosa rather than changes in the clotting system. For Juttner et al. [32], other haemostatic defects may also contribute to epistaxis in dogs with leishmaniasis, particularly in the advanced stages of the disease. Petanides et al. [33] suggest that a single pathogenic mechanism can not be incriminated for epistaxis in natural canine visceral leishmaniasis, but rather the interaction of various internal factors.

Bleeding time is a less sensitive in vivo test of platelet function and its prolongation indicates platelet aggregation or adhesion defect. In this case, prolonged bleeding time can be attributed to vascular damage and thrombocytopenia. Domíngues and Torano [34] demonstrated that in the initial phases of infeccion, the Leishmania was able to interact directly with platelets by a specific mechanism causing formation of large aggregates. High concentrations of gammaglobulin may be associated with circulating immune complexes, common in canine visceral leishmaniasis $[35,36]$, which may either be deposited on the vascular wall causing endothelial defects, platelet-platelet interaction disturbances and/or interaction deficiency between the platelets and the damaged subendothelium by coating the platelets and inhibiting degranulation and/or adhesion according to Juttner et al. [32]. Moreno et al. [17] reported an prolonged bleeding time in the presence of a normal platelet count in dogs with high plasma creatinine levels, attributing this finding to the platelet dysfunction associated with renal failure.

Thrombocytopenia has been related in canine visceral leishmaniasis $[8,37,38]$ and ascribed to immune-mediated destruction triggered by the presence of immune complexes leading to the formation of anti-platelet antibodies, vasculitis resulting in a decrease of platelets [2] and the rapid consumption of platelets resulting from disseminated intravascular coagulation [7]. Unfortunately, it was not possible to evidence that these factors influenced thrombocytopenia developed by this dog, as well as hepatomegaly and splenomegaly. In other studies [17,32], a normal platelet count has been attributed in both stages of the disease (acute and chronic). 
In the present study, both prolonged activated partial thromboplastin time and prothrombin time were apparent. Prolonged PT can be explained by disseminated intravascular coagulation with a reduction of the clotting factors involved in extrinsic and common pathways. Ciaramella et al. [19] observed normal PT values and attributed this finding to either the low sensitivity of the commercial PT tests on plasma canine or to a faster consumption of one or more of the intrinsic pathway clotting factors employed as activators in the formation of inflammatory chemical mediators [39]. Moreno [21] also declared normal m-OSPT (modified one-stage prothrombin time) possibly explained by the different degree of hepatic injury and the absence of disseminated intravascular coagulation. Badylak et al. [40] have reported prolonged one-stage prothrombin time in dogs with hepatic damage. In our case liver enzymes were not measured. Prolonged APTT can be justified by disseminated intravascular coagulation with a reduction in clotting factors involved in intrinsic and common pathways. This finding can also be related to renal failure or to liver disease, which may result in coagulation factor deficiency impairing the synthesis, although renal and liver enzymes were not measured in this case. Font et al. [7] reported a prolonged APPT in a dog with visceral leishmaniasis that had multiple hemorrhagic foci in the hepatic parenchyma. Moreno [21] also described prolonged APPT, even though bleeding was not always present. Valladares et al. [8] observed normal PT and APPT values in dogs with experimentally induced leishmaniasis. According to Ruiz de Gopegui et al. [41], PT and APTT within the reference interval may be seen appear in patients with early and compensated DIC.

The presence of circulating derivatives of fibrin degradation products can be linked to disseminated intravascular coagulation in this dog. In canine leishmaniasis, an increase in the concentration of fibrin degradation products has also been reported and accounted to either the renal loss of antithrombin III with a subsequent hypercoagulability state and increased fibrinolysis [42] or disseminated intravascular coagulation [7,8]. Moreno et al. [21] did not established differences in the levels of fibrin degradation products in their study.

\section{Conclusion}

Several mechanisms can lead to activation of intravascular coagulation, including endotheial damage, platelet activation and release of tissue procoagulants. In canine visceral leishmaniasis, endotheial damage induced directly by Leishmania and the deposition of immuncomplexes appear to play a role in triggering disseminated intravascular coagulation. Thus, dogs naturally infected by Leishmania (Leishmania) chagasi can develop disseminated intravascular coagulation, which seems to be associated with several immunological and pathological mechanisms involved in the disease.

\section{Abbreviations}

DIC: Disseminated intravascular coagulation; BT: Bleeding time; IIF: Indirect ImmunoFluorescence; NNN: Novy, MacNeal and Nicolle; MLEE: Multi-locus enzyme electrophoresis; CBC: Complete blood count; PCV: Packed cell volume; RBC: Red blood cell; FVIla: Activated factor VII; TFPI: Tissue factor pathway inhibitor; PAI-1: Plasminogen activator inhibitor type 1;

FXa: Activated factor X; PT: Prothrombin time; APTT: Activated partial thromboplastin time; $\mathrm{m}$-OSPT: Modified one-stage prothrombim time.

\section{Competing interests}

None of the authors has any financial or personal relationships that could inappropriately influence or bias the content of the paper.

\section{Authors' information}

English review and revision by Mitchell Raymond Lishon, native of Chicago, Illinois, U.S.A. - U.C.L.A.1969.

\section{Authors' contributions}

$\mathrm{COH}$ and TMVP were responsible for the study design. $\mathrm{COH}$ and FBF were responsible for the collection of biological samples and clinical examination of the animal. NXA was responsible for the laboratorial parameters. MFM carried out the parasitological diagnosis and characterization of the parasite. $\mathrm{COH}$ and IDFG drafted the manuscript. $\mathrm{COH}$, FBF, NXA and TMVP were involved in work supervision and writing of the manuscript. All authors read and approved the final manuscript. $\mathrm{COH}$ and TMVP are guarantors of the paper.

\section{Acknowledgements}

The authors thank the Municipal Health Department of Rio de Janeiro and the technicians of the Zoonosis Control Center (ZCC) Paulo Darcoso Filho (Santa Cruz, Rio de Janeiro, Brazil) for the identification and collection of the seroreactive dog and the Jorge Luiz Nunes da Silva for the laboratorial support.

\section{Author details}

'Laboratório de Pesquisa Clínica em Dermatozoonoses em Animais Domésticos, Instituto de Pesquisa Clínica Evandro Chagas, Fundação Oswaldo Cruz (Fiocruz), Av. Brasil, 4365, Manguinhos, Rio de Janeiro 21045-900, Brasil. Laboratório Clínico Veterinário, Departamento de Patologia Clínica Veterinária, Faculdade de Veterinária, Universidade Federal Fluminense, Rua Vital Brasil Filho, 64, Niterói, Rio de Janeiro 24230-340, Brasil. ${ }^{3}$ Laboratório de Vigilância em Leishmaniose, Instituto de Pesquisa Clínica Evandro Chagas, Fundação Oswaldo Cruz (Fiocruz), Av. Brasil, 4365, Manguinhos, Rio de Janeiro 21045-900, Brasil.

Received: 26 September 2012 Accepted: 9 February 2013 Published: 5 March 2013

\section{References}

1. Levi M, Ten Cate H: Disseminated intravascular coagulation. N Engl J Med 1999, 341:586-592.

2. Meyer DJ, Harvey JW: Evaluation of hemostasis: Coagulation and Platelet Disorders. In Veterinary Laboratory Medicine: Interpretation and Diagnosis. 3rd edition. Edited by Meyer DJ, Harvey JW. St. Louis: Saunders; 2004:107-131.

3. Levi M: Disseminated intravascular coagulation. Crit Care Med 2007, 35:2191-2195.

4. Mishra P, Dixit A, Chatterjee T, Bhattacharya M, Bhattacharya J, Dutta P, Mahapatra M, Pati HP, Choudhry VP, Saxena R: Disseminated intravascular coagulation as unusual presentation of kala-azar: report of two cases. Scand J Infect Dis 2004, 36:519-521.

5. al-Jurayyan NA, al-Nasser MN, al-Fawaz IM, al Ayed IH, al Herbish AS, alMazrou AM, al Sohaibani MO: The haematological manifestions of visceral leishmaniasis in infancy and childhood. J Trop Pediatr 1995, 41:143-148.

6. Blount ER, Hartmann R, Nernoff J: Kala-azar as a cause of disseminated intravascular coagulation. Clin Pediatr (Phila) 1980, 19:139-140.

7. Font A, Gines C, Closa JM, Mascort J: Visceral leishmaniasis and disseminated intravascular coagulation in a dog. Am Vet Med Assoc 1994, 204:1043-1044. 
8. Valladares JE, Ruiz De Gopegui R, Riera C, Alberola J, Gállego M, Espada Y, Portús M, Arboix M: Study of haemostatic disorders in experimentally induced leishmaniasis in Beagle dogs. Res Vet Sci 1998, 64:195-198.

9. Coles EH: Patologia Clínica Veterinária. São Paulo: Manole; 1984.

10. Aoki T, Tomiyama Y, Honda S, Mihara K, Yamanaka T, Okubo M, Moriguchi A, Mutoh S: Association of the antagonism of Von Willebrand factor but not fibrinogen by platelet $a_{11 b} \beta_{3}$ antagonism with prolongation of bleeding time. J Thromb Haemost 2005, 3:2307-2314.

11. Ministério da Saúde: Manual de Vigilância e Controle da Leishmaniose Visceral. Série A. Normas e Manuais Técnicos. Brasília: Editora do Ministério da Saúde; 2006

12. Cupolillo E, Grimaldi G Jr, Momen H: A general classification of the New World Leishmania using numerical zymotaxonomy. Am J Trop Med Hyg 1994, 50:296-311.

13. Saba HI, Morelli GA: The pathogenesis and management of disseminated intravascular coagulation. Clin Adv Hematol Oncol 2006, 4:919-926.

14. Levi M: Current understanding of disseminated intravascular coagulation. BrJ Haematol 2004, 124:567-576.

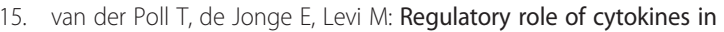
disseminated intravascular coagulation. Semin Thromb Hemost 2001, 27:639-651.

16. Opal SM, Esmon CT: Bench-to-bedside review: functional relationships between coagulation and the innate immune response and their respective roles in the pathogenesis of sepsis. Crit Care 2003, 7:23-38.

17. Moreno P, Lucena R, Ginel PJ: Evaluation of primary haemostasis in canine leishmaniasis. Vet Rec 1998, 142:81-83.

18. Ciaramella P, Corona M: Canine leishmaniasis: clinical and diagnostic aspects. Compend Contin Educ Pract Vet 2003, 25:358-369.

19. Ciaramella P, Pelagalli $A$, Cortese $L$, Pero ME, Corona M, Lombardi $P$, Avallone L, Persechino A: Altered platelet aggregation on coagulation disorders related to clinical findings in 30 dogs naturally infected by Leishmania infantum. Vet J 2005, 169:465-467.

20. Binhazim AA, Chapman WL, Latimer KS, Styles M, Comer L: Canine leishmaniasis caused by Leishmania leishmania infantum in two Labrador Retrievers. J Vet Diagn Invest 1992, 4:299-305.

21. Moreno P: Evaluation of secondary haemostasis in canine leishmaniasis. Vet Rec 1999, 144:169-171.

22. Ciaramella P, Oliva G, Luna RD, Gradoni L, Ambrosio R, Cortese L, Scalone A, Persechino A: A retrospective clinical study of canine leishmaniasis in 150 dogs naturally infected by Leishmania infantum. Vet Rec 1997, 141:539-543.

23. Koutinas AF, Polizopoulou ZS, Saridomichelakis MN, Argyriadis D, Fytianou A, Plevraki KG: Clinical considerations on canine visceral leishmaniasis in Greece: a retrospective study of 158 cases (1989-1996). J Am Anim Hosp Assoc 1999, 35:376-383.

24. Binhazim AA, Chapman WL Jr, Shin SS, Hanson WL: Determination of virulence and pathogenesis of a canine strain of Leishmania leishmania infantum in hamsters and dogs. Am J Vet Res 1993, 54:113-121.

25. Tafuri WL, de Oliveira MR, Melo MN, Tafuri WL: Canine visceral leishmaniosis: a remarkable histopathological picture of one case reported from Brazil. Vet Parasitol 2001, 96:203-212.

26. Almeida MA, Jesus EE, Sousa-Atta ML, Alves LC, Berne ME, Atta AM: Clinical and serological aspects of visceral leishmaniasis in northeast Brazilian dogs naturally infected with Leishmania chagasi. Vet Parasitol 2005, 127:227-232.

27. Tafuri WL, Tafuri WL, Barbosa AJ, Michalick MS, Genaro O, França-Silva JC, Mayrink W, Nascimento E: Histopathology and immunocytochemical study of type 3 and type 4 complement receptors in the liver and spleen of dogs naturally and experimentally infected with Leishmania (Leishmania) chagasi. Rev Inst Med Trop Sao Paulo 1996, 38:81-89.

28. Rallis T, Day MJ, Saridomichelakis MN, Adamama-Moraitou KK, Papazoglou L, Fytianou A, Koutinas AF: Chronic hepatitis associated with canine leishmaniosis (Leishmania infantum): a clinicopathological study of 26 cases. Comp Pathol 2005, 132:145-152.

29. Barrouin-Melo SM, Larangeira DF, Santos SO, Chagas-Júnior AD, Paixão M, Aguiar PH, dos-Santos WL, Pontes-de-Carvalho L: A standardized cytological and immunochemical method for the analysis of fine-needle spleen aspirates: assessment of leukocyte population changes in canine visceral leishmaniosis. Vet Immunol Immunopathol 2006, 111:251-261.

30. Lima WG, Oliveira PS, Caliari MV, Gonçalves R, Michalick MS, Melo MN, Tafuri WL, Tafuri WL: Histopathological and immunohistochemical study of type
3 complement receptors (CD11b/CD18) in livers and spleens of asymptomatic and symptomatic dogs naturally infected with Leishmania (Leishmania) chagasi. Vet Immunol Immunopathol 2007, 117:129-136.

31. Costa FA, Goto H, Saldanha LC, Silva SM, Sinhorini IL, Silva TC, Guerra JL: Histopathologic patterns of nephropathy in naturally acquired canine visceral leishmaniasis. Vet Pathol 2003, 40:677-684.

32. Jüttner C, Rodríguez Sánchez M, Rollán Landeras E, Slappendel RJ, Fragío Arnold C: Evaluation of the potencial causes of epistaxis in dogs with natural visceral leishmaniais. Vet Rec 2001, 149:176-179.

33. Petanides TA, Koutinas AF, Mylonakis ME, Day MJ, Saridomichelakis MN, Leontides LS, Mischke R, Diniz P, Breitschwerdt EB, Kritsepi M, Garipidou VA, Koutinas CK, Lekkas S: Factors associated with the occurrence of epistaxis in natural canine leishmaniasis (Leishmania infantum). J Vet Intern Med 2008, 22:866-872.

34. Domínguez $M$, Toraño $A$ : Leishmania immune adherence reaction in vertebrates. Parasite Immunol 2001, 23:259-265.

35. Brandonisio O, Carelli G, Altamura M, Varvara B, Ceci L: Circulating immune complexes and autoantibodies in canine leishmaniasis. Parassitologia 1990, 32:275-281.

36. Saridomichelakis MN: Advances in the pathogenesis of canine leishmaniosis: epidemiologic and diagnosis implications. Vet dermatol 2009, 20:471-489.

37. Alvar J, Molina R, San Andrés M, Tesouro M, Nieto J, Vitutia M, González F, San Andrés MD, Boggio J, Rodriguez F, et al: Canine leishmaniasis: clinical, parasitological and entomological follow-up after chemotherapy. Ann Trop Med Parasitol 1994, 88:371-378.

38. Costa-Val AP, Cavalcanti RR, Gontijo NF, Michalick MSM, Alexandrer B, Williams P, Melo MN: Canine visceral leishmaniasis: Relationships between clinical status, humoral immune response, haematology and Lutzomyia (Lutzomyia) longipalpis infectivity. Vet J 2007, 174:636-643.

39. Jimenez C, Fernandez F: Inflammation, kinins, and complement. System interation with haemostasis. In Schalm's Veterinary Hematology. 5th edition. Edited by Feldman BF, Zinkl JG, Jain NC. Philadelphia: Lippincott Williams and Wilkins; 2000:549-551.

40. Badylak SF, Dodds WJ, Van Fleet JF: Plasma coagulation factor abnormalities in dogs with naturally occurring hepatic disease. Am J Vet Res 1983, 44:2336-2340.

41. Ruiz de Gopegui R, Espada Y, VilaFranca M, Cuadradas C, Fontcuberta E, Millá F, Roncalés J, Ruzafa A: Paraprotein-induced defective haemostasis in a dog with OGA (kapa-light chain) forming myeloma. Vet Clin Pathol 1994, 23:70-71.

42. Font A, Closa JM, Molina A, Mascort J: Thrombosis and nephrotic syndrome in a dog with visceral leishmaniasis. J Small Anim Pract 1993, 34:466-470

doi:10.1186/1746-6148-9-43

Cite this article as: Honse et al:: Disseminated intravascular coagulation in a dog naturally infected by Leishmania (Leishmania) chagasi from Rio de Janeiro - Brazil. BMC Veterinary Research 2013 9:43.

\section{Submit your next manuscript to BioMed Central and take full advantage of:}

- Convenient online submission

- Thorough peer review

- No space constraints or color figure charges

- Immediate publication on acceptance

- Inclusion in PubMed, CAS, Scopus and Google Scholar

- Research which is freely available for redistribution 